\section{6 \\ DIFFERENTIAL DIAGNOSIS OF CHILDHOOD ABUSIVE INJURY FROM UNINTENTIONAL INJURY BASED ON BODYGRAPHICAL INFORMATION OF INJURY}

doi:10.1136/injuryprev-2012-040590d.56

${ }^{1} \mathrm{~K}$ Kitamura, ${ }^{1} \mathrm{Y}$ Nishida, ${ }^{2} \mathrm{~T}$ Yamanaka. ${ }^{1}$ Digital Human Research Center, National Institute of Advanced Industrial Science and Technology (AIST), Japan; ${ }^{2}$ Ryokuen Children's Clinic, Japan

Background/Purpose Although it is important to distinguish abusive injury from accidental injury, there is no standard differential diagnosis methods based on the data. One of useful information is data on injured body parts. It is said that its trends are different, but there is no tools for judging the difference based on the data. The purpose of this study is to develop a system for supporting differential diagnosis based on the data on injured body parts.

Methods We have developed a system for collecting data on injured body parts for preventing childhood unintentional injury. This system enables us to describe injured body parts by painting on the three-dimensional shape model of a child. By overlaying data of multiple cases, the system calculates frequency distribution of injury. So far we've collected more than 16000 unintentional injury data. Based on these data, we developed a system that computes probability of injury due to accident by calculating similarity between injury suspected of abuse and unintentional injury.

Using data of 40 cases suspected of abuse, we verified the usefulness of developed system. The average of probability is 0.10 $(\mathrm{SD}=0.13)$. Since 40 cases are suspected of abuse, the result is reasonable and it indicates the usefulness of our system.

Conclusion We developed the system for supporting differential diagnosis based on data about injured body part. The usefulness of developed system was verified. Now we are verifying the feasibility in cooperation with a child guidance centre and some kindergarten. 